\title{
The Impact of Psychological Factors on Employees in the IT\&C Environment
}

\author{
Andrei NICULESCU*, Olivia Doina NEGOITA, \\ Mirona Ana-Maria POPESCU, Anca Alexandra PURCĂREA \\ University Politehnica of Bucharest, Faculty of Entrepreneurship, Business Engineering and Management \\ 313 Splaiul Independenței, Bucharest, 060042, Romania \\ andrei@niculescu.ro (*Correspondingauthor), negoita.olivia@gmail.ro, \\ mirona.popescu15@gmail.com, apurcarea@gmail.com
}

\begin{abstract}
The IT industry is constantly growing and it is the main contributing factor to the transformation and efficiency of the economy and society. The demand for services and software has led to the emergence of many companies, which are often hard to distinguish from one another and furthermore can hardly maintain their position on the market. The key element that contributes to the development of programs and their quality is represented by the human resources of IT\&C. Retaining competent employees in this field is a real challenge, because the competition among the numerous companies is very tough. In order to gain projects, the IT\&C employees should have a proper package of knowledge and experience. Thus, this article analyses several psychological factors affecting IT\&C professionals. By using Statistical Package for the Social Sciences (SPSS) the paper determines the correlation matrix that provides different IT\&C work-related data ranked in order of importance. Also, some relationships between variables (level of study, time spent in this field and in the respective company) and certain psychological factors (temper, psychological type, professional behavior) are briefly examined.
\end{abstract}

Keywords: Human resouces, Psychological factors, IT field, IT\&C employees, IT\&C organizations.

\section{Introduction}

The evolution of the IT\&C sector is largely due to two main factors: quality college education in technology and fiscal incentives for this industry (a $0 \%$ tax on programmer's income or state aid for job creation in the field are only two examples of such incentives). As a consequence, more and more IT centres and R\&D hubs emerged in Romania in the last years. However, employers have started facing significant problems in the recruitment process, simply because the number of candidates on the market is not very high. The importance of motivating a person to work in a technology company is currently considered a challenge, because there are numerous workplaces that offer a wide range of benefits to their employees, such as diversified technologies, attractive salaries, as well as interesting projects with a a significant impact on the market.

A significant factor in the process of research and development related to programs and deliverables in the field of IT\&C is the management of human resources with high qualifications, accredited by trustworthy sources and that can be identified by the candidates both during and after the recruitment process, by involving them in the assigned tasks and in their completion within the agreed parameters. Motivating staff with a high qualification level and who represents a key element in every project within the company has become a complex process that is getting more and more attention in Romania. The creation of a stimulative environment for research and development that offers satisfaction to the employees in this field is based on performance and on taking into consideration employee feedback, by treating each of them as an individual and understanding every employee independently.

Consolidating this environment and keeping it at actual standards and at the current HR market requirement level, in a perpetual process of change and evolution, which focuses on the employee as the key element, represents a basic condition for company performance growth and human resources satisfaction in the IT\&C sector.

This is why the present article, though its research work, is aiming at pointing out which are the main drivers behind employee satisfaction and motivation in the Romanian IT\&C industry.

The present article highlights the initial results obtained by launching a questionnaire among Bucharest based technology companies that create $\mathrm{R} \& \mathrm{D}$ programs and services for the IT\&C sector, in the period May - November 2018. The targeted problems refer to identifying the factors that determine employees to choose this domain and their motivation to develop and to evolve within the company.

The necessity for such a research is evident, given the current disproportion between supply and demand in the field of IT\&C labor force. The importance of this study is given by the need for companies in this sector to use their human 
resource as the main competitive advantage in an ever more demanding global capitalist system.

Section 2 treats the scientific context as a whole, starting with the general IT\&C environment in Romania, defining and describing cognitive and affective motivation, personality and professional employee behaviour and ending with a selective bibliographical research on the subject of motivation in the IT\&C sector. Section 3 deals with the metodology of obtaining the data and describes the analytical procedures used for the research, while section 4 presents the results of the research, the data sample, the correlation matrix and some key findings. The final section offers the conclusions.

\section{Scientific Context}

\subsection{The IT\&C Environment}

The IT\&C sector has special requirements when it comes to attracting new employees and especially to retaining them. IT services and software companies in Romania are making considerable efforts to retain their best employees, especially in the R\&D field.

Even if the crisis years after 2008 had triggered lowered staff turnover and fewer requests for salary increases, starting with 2014, the HR departments of these companies have started to deal with the new tendencies on the labour market, such as new requests from the part of the employees and a strong domestic competition. The IT\&C sector differentiates itself from the others by the need for specialists operating in software companies, and the supply of trained staff capable to satisfy this need appears to be surpassed by the current market demand. The current challenge for the IT\&C and software job market translates into the need to train specialists that are able to keep up with the constantly changing technology trends. This challenge is particularly present in the field of R\&D, as Kochanski (2001) and Jordan (2005) point out.

Employers have understood the competitive game on the job market and are currently rethinking different tactics in their endeavor to acquire quality employees. Some of them have closed partnerships with technology colleges and universities, while others are managing internship programs followed by the hiring of the newly trained.
After the recruitment process, the challenge mainly consists in maintaining the employed staff. Salaries in the IT\&C sector are no longer an essential factor in motivating employees and in keeping them working for the current company. Salaries are generous throughout the job market compared to other industries, so the employees' requests and expectations usually go beyond financial benefits. Companies now offer gym memberships, work from home schedules, free workplace massage facilities, pool memberships, access to virtual libraries, private medical insurance and discounts for different spas, attendance at international conferences and trainings, access to state-of-the-art technological devices, supplementary vacation or even an unlimited number of free days as compensation for supplementary work. Moreover, companies are striving to create a relaxing working environment by setting up fully equipped playrooms, in order to support the idea of relaxing the staff and stimulating creativity. Some companies offer additional training programs that are targeting not only technical expertise, but also the acquisition of soft skills, such as management, leadership and public speaking skills, for preparing future leaders and advancement opportunities.

The deficit of specialist R\&D staff has pushed companies to take even more atypical measures by encouraging their own employees to "hunt down" candidates from their academic environment or from within their circle of friends or acquaintances.

\subsection{Cognitive and Affective Motivation}

Cognitive motivation is peculiar to the intelectual side of the employees and focuses on satisfying their individual need to be permanently informed, to know, to learn, to get involved in innovative actions, to operate and to hold a certain degree of control over the environment in which they work. Managers target the entire motivational system formally, informally, economically, morally and spiritually, with the purpose of fulfilling cognitive motivation.

Affective motivation refers strictly to the human side of the employee, focusing on their emotional needs within the company. This type of motivation takes into consideration how the employees feel at the workplace, their degree of appreciation from the team, the relationship with their colleagues, as well as with their superiors and subordinates, manifestations of consideration, sympathy and

https://www.sic.ici.ro 
the possibility to enjoy fame or prestige at the workplace. Affective motivation can be achieved if all the moral and spiritual incentives are used and it is focused on satisfying the emotional expectations of employees, with a significant energizing role for the performance of each employee.

Performance represents a function of the interaction between cognitive, affective and motivational capacity and it was analysed by Van Iddekinge et al. (2018). The researcher has made a meta-analysis and has noticed that $91 \%$ of workplace performance is the result of additional effects of capacity and motivation, with only $9 \%$ being the result of the interaction between capacity and motivation from the explicit scenario. These conclusions have an impact on talent management practices concerning human resources acquisition and performance.

The problem of how motivation affects creativity is approached by $\mathrm{Li}, \mathrm{Li} \&$ Chen (2018). This study suggests a motivational-cognitive creativity model starting from the motivational theory of information processing, and the results have offered empirical evidence for this hypothesis, have identified workplace autonomy to be directly and positively linked with creativity through motivation and cognitive flexibility.

\subsection{Personality, Psychological Types and Professional Behaviour}

Personality consists of character and temperament. Generally, in each person there is a different percentage of the four types of personality: choleric, sanguine, melancholic and phlegmatic, some being more prevalent and outlining the individuality of each individual, as per Riso (1996).

Professional behavior depends on the type of personality and environmental influences, thus we can define more types of professional behaviours according to C.G. Jung (1946):

Ambitious: he/she is highly competitive, works at a fast pace, assumes responsibilities, his/ her position in the system (organization) he/ she belongs to is important to him/her, showing upward social comparison tendencies.

Professional: he/she seeks a profession corresponding to his/her professional skills and level of knowledge, in which individual merits are recognized and where experience exchange is possible; wants to be in touch with the new discoveries; is creative, prefers abstract theoretical issues; appreciates a competent chief who is at least equal, if not superior; has a cognitive motivation.

Company-oriented: wants to work in a wellknown organization with modern buildings and utilities without a fixed schedule, where work is highly important; comfort and very good working conditions are targeted when looking for a job (stylish office, recognized group, security, pleasant geographical climate).

Analyst: he/she likes to work alone; he/she is a reflexive spirit, analyzes problems in depth, seeking the best solution; does everything with passion, preferring interesting issues; within the team, he/ she is the person who is frequently asked for help.

Team player: he/she prefers working in a group, in problem solving situations; develops plans, has a good overall vision; is well-organized, finds solutions to get out of difficult situations; is autonomous; is looking for a profession to give $\mathrm{him} /$ her the freedom he or she needs (relaxed work schedule, free working climate); prefers work that does not have to adhere to company policy; prefers uncompetitive situations where wages and promotions come automatically.

Jung (1946) also split human psychic energy into two fundamental attitudes: introversion and extraversion, based on which the psychoanalyst developed a framework of four psychological functional types: reflective, affective, sensorial and intuitive. Each of the resulting psychological types develop a different behaviour, that in turn influences professional behaviour, on which the present article is focused. The questionnaire respondents were included in half of the eight major psychological types of Jung, as shown in Table 1, each with its professional behaviour counterpart.

Table 1. Psychological Types

\begin{tabular}{|c|c|}
\hline Type & Definition \\
\hline Reflective-extraverted & $\begin{array}{c}\text { analytical, strategic, planner, } \\
\text { implements, organizes others }\end{array}$ \\
\hline Reflective-introverted & $\begin{array}{c}\text { contemplative, theoretical, discovers, } \\
\text { seeks self-knowledge }\end{array}$ \\
\hline Affective-extraverted & $\begin{array}{c}\text { sociable, sentimental, pursues } \\
\text { personal and social success }\end{array}$ \\
\hline Intuitive-introverted & $\begin{array}{c}\text { idealistic, visionary, esoteric, } \\
\text { mystical, reserved }\end{array}$ \\
\hline
\end{tabular}

\subsection{Research on Motivation in IT\&C}

The motivations of software developers have been studied over the last 10 years. Von Krogh 
et al. (2012) propose a theoretical framework for individual long-term motivation, consisting of three theoretical conjectures that are meant to highlight the way employees are determined to implement quality software, change companies, and support open source development. Their approach gives a perspective on how motivational factors may impact tech employees, and is further researched by the current paper. Rigby \& Richard (2018) study the ways in which a company can motivate and stimulate employees, so as to generate a stronger commitment to the company and meet the demands of the employees. The study highlights different methods of motivating employees and gave the authors another point of view for the present research.

In their study, Collins \& Smith (2006) focus on how human resources impact the organizational social climate conditions that contribute to the performance of companies. The result of this study is relevant for companies to invest resources in human capital and understand its importance in an organization. The results are also strengthened by Chatterjee (2017), according to whom human capital investment is essential in knowledgebased industries in order for them to keep their competitive advantage. Their study demonstrates that an IT firm which aims to grow rapidly is empowered to improve its employees' capabilities through internal development. This highlights the need to research present motivational factors for IT employees, study that is carried out in the current paper.

Muratbekova-Touron \& Galindo (2018) analyze the management of software developing companies from the employees' point of view. They use interviews to collect the necessary data and outline the key role of direct managers and of the HR department of an IT company. The results of this study underline the importance of studying professional behaviour of IT employees, which is also tackled in the present article.

The primary objective of Sukriket's study (2018) was to determine the variables that deliver professional satisfaction and which are correlated with the business intentions of IT employees. The main attraction factors studied in this framework were the following: benefits, nature of work and supervision. This research presented the professional satisfaction which is linked to variables studied in the present article, such as personality, temperament and professional behaviour.
Schloegel et al. (2018) pointed out that so far software development has been based on processes and tools, not on social dimensions. Therefore, they investigated the psychological factor of age stereotypes as a social dimension and their findings show that middle-age software developers are favoured. As a result, the present research also deals with and the correlation between employee age groups

Increasing competition among IT firms also leads to the development of IT employees according to Akgün et al. (2017). The study tries to evaluate the provision of information within teams in order to build solutions based on the contribution of the whole team and to determine the existing barriers.

According to Yilmaz et al. (2017), a large number of software projects are failing due to social problems. They tackle the characteristic features of software development employees and a survey is used in order to build a model that illustrates the personality of the team and the structures within it. This survey is particularly relevant for the further development of personality performance correlations that are also the subject of the present article.

The conversion of global virtual teams into parts of global IT outsourcing is a common practice, as Gurung \& Prater (2017) sustain. For this reason, the cultural differences and their impact on IT outsourcing in the last years are analyzed.

\section{Methodology}

\subsection{Obtaining the Data}

The main objective of this research was to determine the motivating factors for the IT\&C employees. The work was empirical and consisted in a questionnaire addressed to a relevant target audience. The questionnaire was developed in Romanian, to ensure a satisfying response rate and consisted of a series of sections. The questionnaire was distributed online to the employees, and the results were translated into English. As its structure is concerned, the first section consisted of a short description of its purpose and of a text ensuring the personal data confidentiality. The second section consisted of questions regarding the present workplace (the position, the number of levels in the organization, the employee's current level, the number of work years in the company, 
the number of work years in the IT\&C industry). The third section consisted of questions related to demographics (age, gender, level of studies, marital status). The fourth section focused on identifying the specific features of the people working in this industry (personality traits, psychological type, motivation factors and hygiene factors). F. Herzberg's (1964) dualfactor theory is one of the most influential and quoted theories in human resource management. According to this fundamental work there are two types of factors in motivational theory: the motivational ones that are intrinsic and establish the relationship of the individual with others, referring to the content of the work and the hygienic ones that are extrinsic and refer to the working environment, ie to the relationship with the organizational environment. The former influence work performance positively through their presence and the latter influence work performance negatively through their absence. This dual-factor perspective was considered when elaborating the questionnaire.

The last section of the questionnaire consisted of open questions and was aimed at identifying the employee drive for the company he/she was currently working for, in order to also identify their main motivation. The motivating factors and the hygiene factors were measured using the Likert scale, with 5 grades (from 1 - very weak to 5 - very strong). The questionnaire allowed the employees not only to evaluate the main factors presented, but also to expose the factors that they consider important for individual satisfaction. The target group consisted of IT\&C employees working both in large companies (multinational companies) and in small companies (SME). This target group was represented only by employees working in the development or maintenance branches, thus in a very well-defined area. The questionnaire was launched in May 2018 and ran for a period of 7 months, being closed in November 2018. We chose the target group and building type specifically for such a short period and to ensure a fast and easy response, in order to capture as many results as possible. The data was collected online, as it was much easier to collect and interpret it this way. This method was also in accordance with the medium which is most used by the target group. The questionnaire was sent to 373 employees, but when the questionnaire was closed, the number of participants was 320 due to some lacking answers.

\subsection{Analytical Procedures}

The methodology consisted in a primary research using the investigation method with a questionnaire as an instrument realised using Google Forms and distributed by email to the target group. The data obtained from the questionnaire was processed using the statistical analysis software IBM SPSS 25.0 on Windows 10 operating system. The collected data was verified and also the obtained values were introduced in order not to alter the results of the questionnaire.

\section{Results}

\subsection{The Data Sample}

According to the information collected, a percentage of $54.5 \%$ of the female respondents and a percentage of $45.5 \%$ of the male respondents occupy positions in this field. The higher number of women opting increasingly for the IT \& C domain, which was previously preferred by the majority of men, is obvious. Out of the total respondents, $18.2 \%$ had between $20-25$ years of age, which means they started to work at an early age, either during or right after the academic studies. A proportion of $36.4 \%$ of respondents were between $26-30$ years of age, $27.3 \%$ between 41-50 years of age and $18.2 \%$ between $31-40$ years of age. $45.5 \%$ of employees have just graduated, with a Bachelor's degree which was enough for them to get hired, and can deepen their knowledge and acquire new knowledge. However, 36.4\% of them continued their studies by attending Master programs. Only $18.2 \%$ of the total respondents opted for $\mathrm{PhD}$ studies, which indicates their importance for IT \& C.

\subsection{The Correlation Matrix}

For data analysis the correlation table (Table 2) was used. This is a dual input table which displays the role of the factorial variable which is taken by the main characteristic $X$ and that of the variable which is taken by the secondary characteristic $\mathrm{Y}$.

This category of coefficients is defined for quantification based on the intensity of the link between the quantitative ecological characteristics but it can be also be adapted for the study of qualitative characteristics.

Their common features are dimensionlessness and a restricted value domain $([-1,1] ; 1$ or $[0,1])$. 
Table 2. Correlation matrix

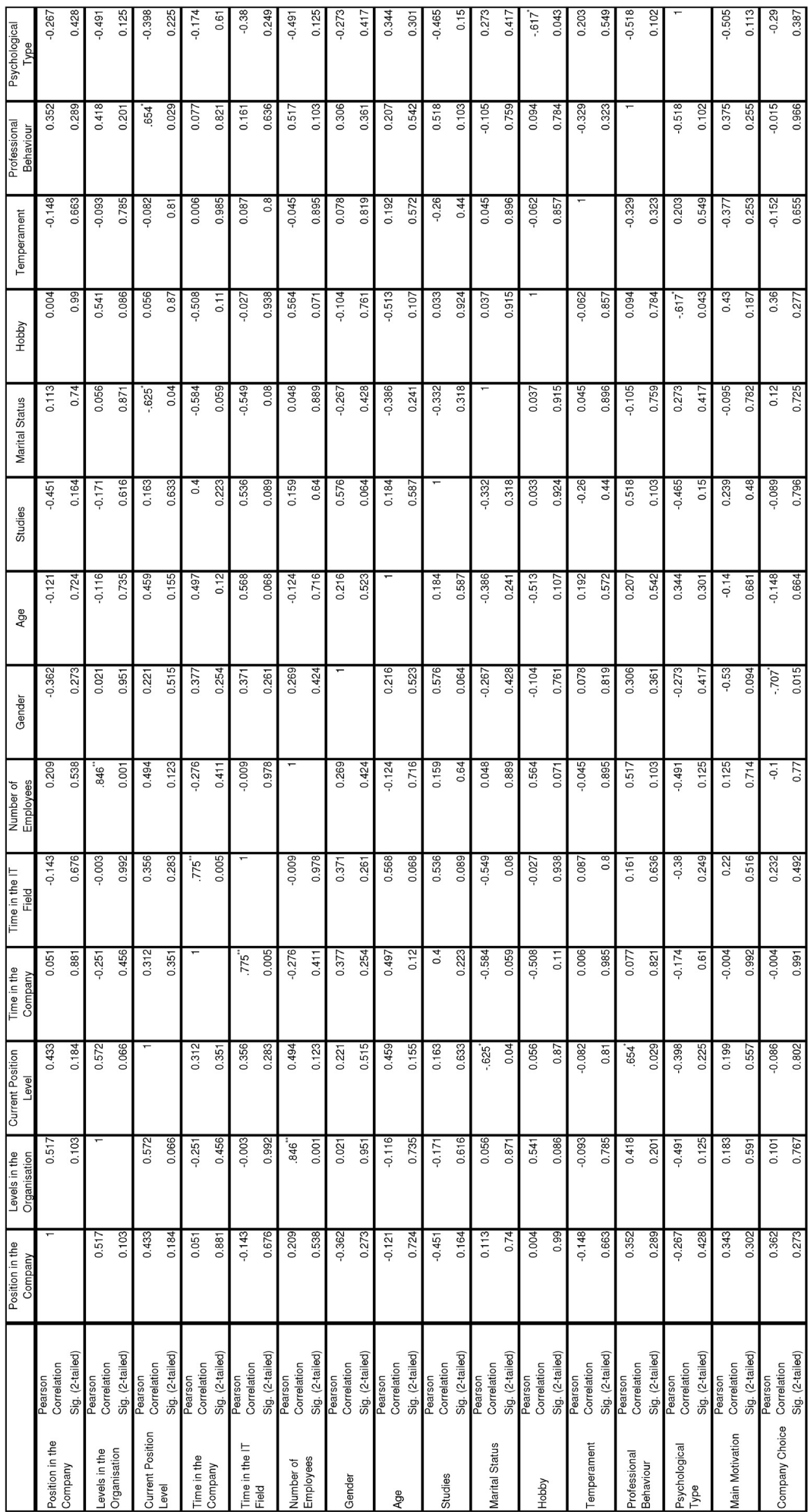




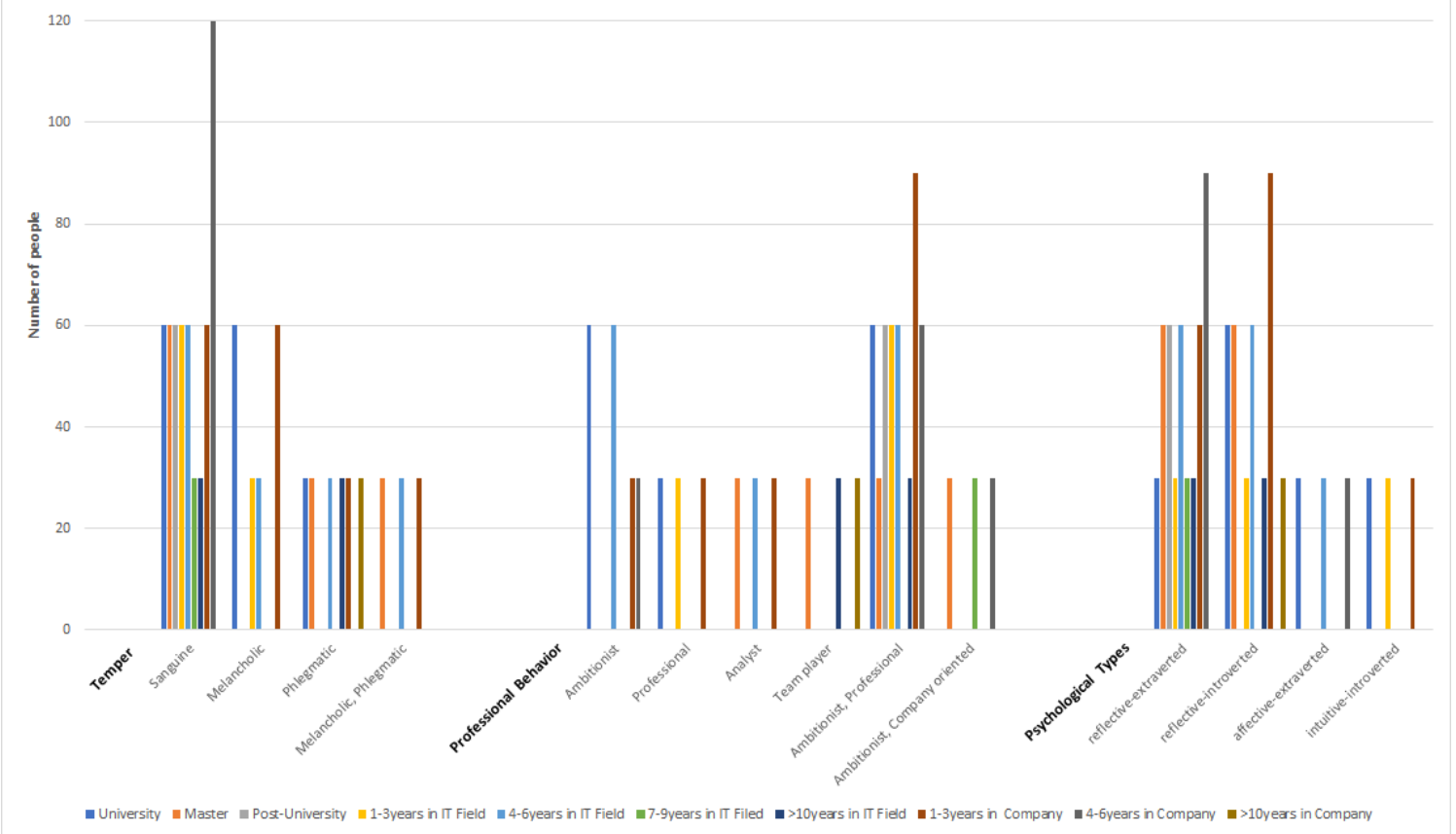

Figure 1. The link between psychological factors and variables (level of education, time spent working in the company, time spent in the IT\&C field)

Extreme values indicate either a maximum or a minimum correlation intensity (Costescu, 2004).

In practice, it is considered that if:

$0 \leq\left|r_{X Y}\right|<0,2$ this indicates that there is no connection between the variables $\mathrm{X}, \mathrm{Y}$;

$0,2 \leq\left|r_{X Y}\right|<0,5$ this indicates that there is a weak link between X, Y;

$0,5 \leq\left|r_{X Y}\right|<0,75$ this indicates that there is a medium intensity link between $\mathrm{X}, \mathrm{Y}$;

$0,75 \leq\left|r_{X Y}\right|<0,95$ indicates that there is a strong link between $\mathrm{X}, \mathrm{Y}$;

$0,95 \leq\left|r_{X Y}\right| \leq 1$ indicates that there is a relatively deterministic relation between $\mathrm{X}$ and $\mathrm{Y}$.

According to the results obtained in the correlation matrix in Table 2, a strong link can be observed between age and number of employees, showing that experienced employees are more likely to be found in larger organisations. Furthermore, this conclusion is strengthened by the highly deterministic correlation between time spent in the IT\&C field (a sign of seniority in the industry) on one hand and both number of levels and number of employees in the company on the other hand. This result shows that more experienced employees are seeking more complex organisations, where they can have a clearer career path and objective system. The professional behaviour is also strongly correlated with the current position in the company and with time spent working for the current company, which means that different behaviour types have different likelihoods of reaching certain hierarchical levels and of continuing to work for the same company.

\subsection{Influence of the Psychological Factors Correlated with the IT Domain}

One of the objectives of this research was to determine how the psychological factors affecting a person influence his/her level of education and his/her commitment to a company and to the IT\&C field. Figure 1 highlights the results of the questionnaire.

The respondents who only had a bachelor's degree have a predominantly sanguine or phlegmatic temperament, being ambitious and professional as their strongest behaviour type, most of them being reflective-introverted.

Most masters degree graduates have a sanguine temperament and the most common professional behaviour types are: analyst, team-player, ambitious, professional and company-oriented. 


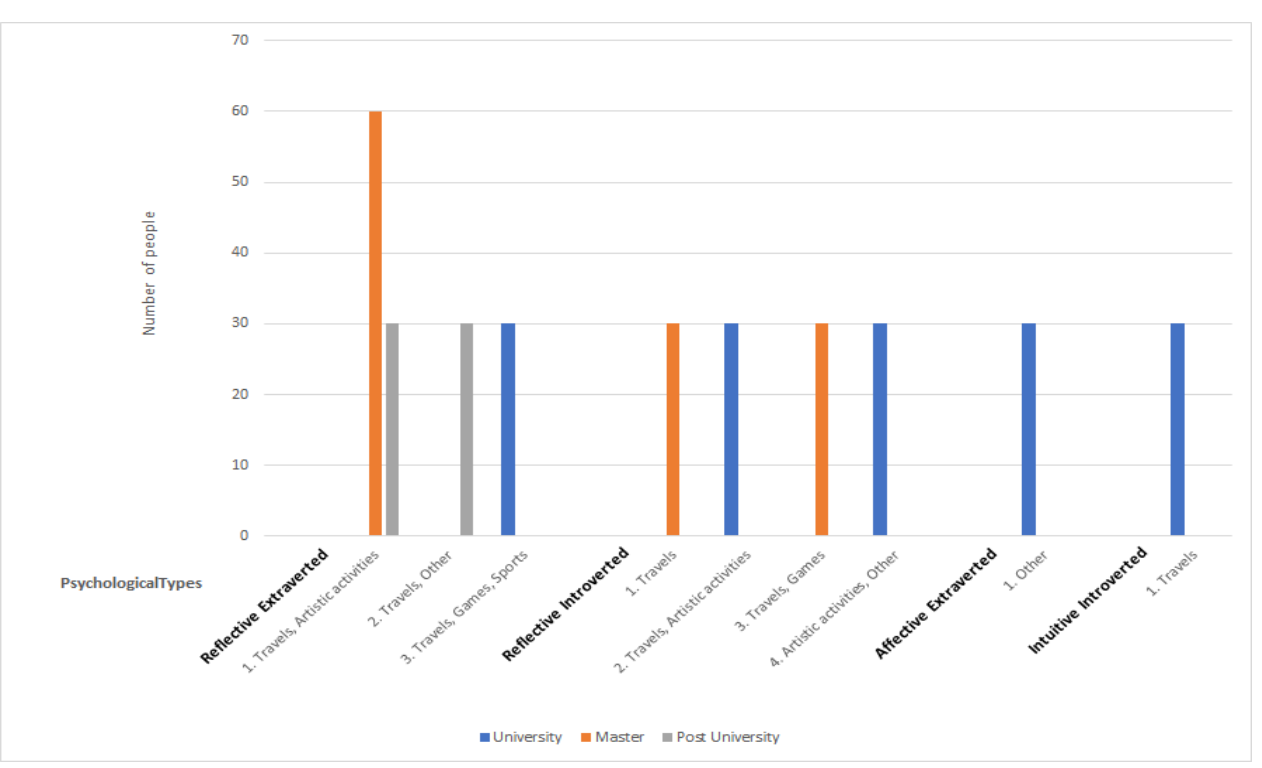

Figure 2. Psychological types vs. Education level vs. Hobbies

Their psychological type is reflective-extraverted and reflective-introverted.

Employees who continued their studies even further have a sanguine temperament and the majority of them are ambitious and professional, with a reflective-extraverted psychological type.

Another aspect treated in this paper concerns hobbies that people who work in IT\&C field have according to the psychological factors and the level of education. Figure 2 presents the psychological types linked to the level of studies and respondents' hobbies. The majority of masters degree graduates are reflective-extraverted and like travels, artistic activities as top of the list, followed by games. Bachelor graduates have a similar percentage in all psychological types and they tend to like games, sports, artistic activities and others. This result can be important for IT\&C employers to prioritize activities, bonuses or other incentives along the lines of their employee's preferences.

Another relevant result is the analysis the responses of various psychological types to different motivational factors. Figure 3 shows a synthesis of this relationship, which illustrates the differences between the perceptions of various psychological types to different motivational factors. The questionnaire included the following motivational factors: flexible schedule, work from home, teambuilding, trainings, performance equipment, medical insurance, benefits card,

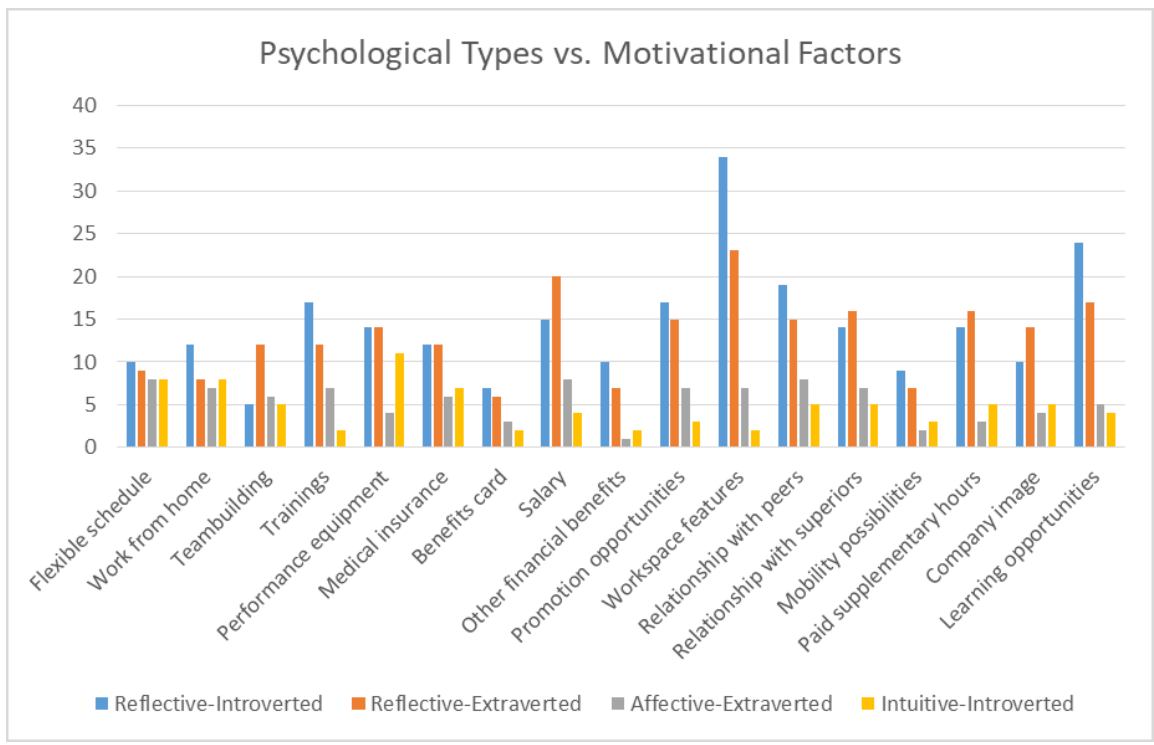

Figure 3. Psychological types vs. Motivational factors 


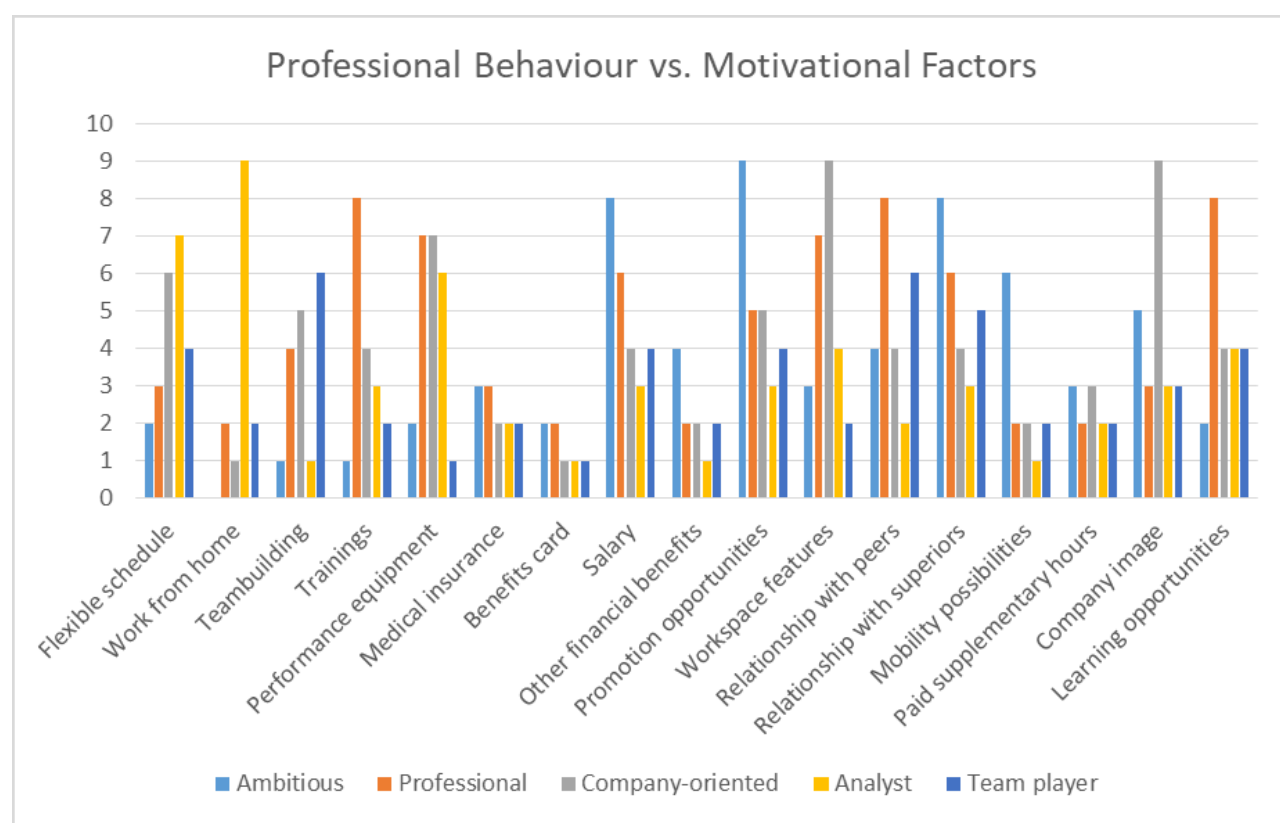

Figure 4. Professional behaviour vs. Motivational factors

salary, other financial benefits (in the form of periodical bonuses, commissions etc.), promotion opportunities, workspace features, relationship with peers, relationship with superiors, mobility possibilities, paid supplementary hours, company image and learning opportunities. The analysis also differentiated the factors between motivational and hygienic, however it made more sense to express them graphically as a cummulated result. For example, workspace features are the most important factor for reflective-introverted types, but one of the least important for intuitiveintroverted types. Affective-extraverted types perceive all motivational factors similarly, with little variation. Learning opportunities are likely to motivate reflective-introverted respondents more than working on performant equipment, whereas for intuitive-introverted types the priorities are inverted. There are multiple such comparisons to be made, and employers can use the data to assess which factors have higher priority for which psychological types among their staff.

Another interesting set of results comes from Figure 4, which shows the correlation between the five types of professional behaviour described at chapter 2.3: ambitious, professional, companyoriented, analyst and team-player and the 17 different motivational factors included in the questionnaire. For ambitious employees, most important factors include salary, promotion opportunities and the relationship with superiors and least important is the possibility to work from home. For professional employees, most important are trainings, relationship with their team members and the learning opportunities. For companyoriented staff, workspace features, company image and performant work equipment are more important than financial motivators, such as salary or other financial benefits. Analysts, because of their particular common personality traits described above, consider working from home and flexible schedules as the most motivating factors, whereas for team-players, the relationship with their peers and teambuildings have the highest value. The results are also important, because employers should take into consideration the large spectrum of their employees' different needs.

\section{Conclusion}

The successful initiation and deployment of a business activity, to an overwhelming extent, depend on the degree to which the human factor is understood, motivated and coordinated. The importance of this aspect is due to the fact that human resources have become an objective of major concern and the main source for the efficiency and profitability of the company.

Human resource management requires a strategic approach to the opportunities of attracting, training, developing, managing, using and motivating the main "key resources" (human resources), through which any organization can ensure the successful achievement of its goals.

Employee motivation, given the ever-growing scarcity of available personnel in the IT\&C sector, 
is becoming an increasingly important strategic concern, both for large multinational, as well as start-ups and smaller technology businesses.

This article proposes various levels of psychological classification instruments that are useful to better understand the needs of IT\&C employees. The research intents to show the manner in which various types of personalities and behaviours respond to different factors that influence work performance. Each company is

\section{REFERENCES}

1. Akgün Ali E., Keskin Halit, Ayar Hayat \& Okunakol Zeki. (2017). Knowledge sharing barriers in software development teams: A multiple case study in Turkey, Kybernetes Journal, 46(4), 603-620.

2. Chatterjee, J. (2017). Strategy, human capital investments, business-domain capabilities, and performance: a study in the global software services industry, Strategic Management Journal, 38(3), 588-608.

3. Collins, Christopher J. \& Smith, K. G. (2006). Knowledge exchange and combination: The role of human resource practices in the performance of hightechnology firms, Academy of Management Journal, 49(3), 544-560.

4. Gurung, A. \& Prater, E. (2017). A research framework for the impact of cultural differences on IT outsourcing, Journal of Global Information Technology Management, 9(1), 24-43.

5. Herzberg, F. (1964). The MotivationHygiene Concept and Problems of Manpower, Personnel Administration, 27, 3-7.

6. Jordan, G. B. (2005). What matters to R\&D workers, Research-Technology Management, 48(3), 23-32.

7. Jung, C. G. (1946). Psychological Types, 5-12. Kegan Paul, Trench, Trubner \& Co., Ltd.

8. Kochanski, J. \& Ledford, G. (2001). "How to keep me" - retaining technical professionals, Research-Technology Management, 44(3), 31-38.

9. Li, H., Li, F. \& Chen, T. (2018). A motivational - cognitive model of creativity and the role of autonomy, Journal of Business Research, 92, 179-188. encouraged and should set-up their HR strategy by offering different incentives to different types of individuals and to always be aware of their employees' psychological structure. Limitations of this study include broadening the scope of the research to other key industries that experience employee recruitment and retention issues, as well as further expanding the list of incentives and extending the sample to more respondents.

10. Muratbekova-Touron, M. \& Galindo, G. (2018). Leveraging psychological contracts as an HR strategy: The case of software developers, European Management Journal, 36(6), 717-726.

11. Rigby, C. Scott \& Ryan, Richard M. (2018). Self-determination theory in human resource development: New directions and practical considerations, Advances in Developing Human Resources, 20(2), 133-147.

12. Riso, Don Richard. (1996). Personality Types: Using the Enneagram for SelfDiscovery, Mariner Books, 213-248.

13. Schloegel, U., Stegmann, S., Maedche, A. \& van Dick, R. (2018). Age stereotypes in agile software development - an empirical study of performance expectations, Information Technology \& People, 31(1), 41-62.

14. Sukriket, P. (2018). The relationship between job satisfaction and turnover intention of Thai software programmers in Bangkok, Thailand, AU Journal of Management, 12(2), $42-52$.

15. Van Iddekinge, C. H., Aguinis, H., Mackey J. D. \& DeOrtentiis, P. S. (2018). A metaanalysis of the interactive, additive, and relative effects of cognitive ability and motivation on performance, Journal of Management, 44(1), 249-279.

16. Von Krogh, G., Haefliger, S., Spaeth, S. \& Wallin, M. W. (2012). Carrots and rainbows: Motivation and social practice in open source software development. MIS Quarterly forthcoming, 36(2), 649-676.

17. Yilmaz, M., O'Connor, R. V., ColomoPalacios, R. \& Clarke, P. (2017). An examination of personality traits and how they impact on software development teams, Information and Software Technology, 86, 101-122. 